\title{
PENDATAAN KEPENDUDUKAN DENGAN METODE POPULATION UNTUK MENDUKUNG OTOMATISASI BASIS DATA DI DESA LUNDO Kec. BENJENG, Kab. GRESIK
}

\author{
Samsuita Imanniar ${ }^{1}$, Iwan Yusuf Kharie ${ }^{2}$, Nurul Fauzul ${ }^{3}$, Anindya Lisa Nirmada ${ }^{4}$ \\ ${ }^{1,2}$ Fakultas Teknik Sipil dan Perencanaan Universitas PGRI Adi Buana Surabaya \\ ${ }^{3,4}$ Fakultas Keguruan dan Ilmu Pendidikan Universitas PGRI Adi Buana Surabaya \\ Email: isamsuita@gmail.com¹, f4uzuL.1990@gmail.com³
}

\begin{abstract}
Divisi kependudukan merupakan salah satu program kegiatan KKN-PPM UNIPA 2017 yang bekerja dibidang kependudukan dan pendataan desa.Devisi ini berfungsi untuk mengumpulkan data baik data profil desa, kependudukan, maupun potensi dan masalah desa Lundo.Desa Lundo merupakan salah satu desa yang memiliki data kependudukan yang cukup baik.Berdasarkan data tersebut dapat diketahui bahwa Desa Lundo memiliki berbagai potensi serta masalah.Salah satu potensi yang terbesar adalah pada bidang pertanian serta kerajinan dan industri kecil yang tersebar merata di 6 dusun Desa Lundo.Metode yang digunakan untuk menggali data tersebut adalah dengan melakukan pendekatan pada staff pemerintahan Desa Lundo serta survey primer.Data-data tersebut kemudian diolah menjadi peta administrasi, potensi desa, penggunaan lahan dan persebaran sarana.Pendekatan tersebut dilakukan selain untuk menggali data, juga dilakukan untuk memperkenalkan aplikasi "population" yang digunakan untuk menginput data kependudukan.
\end{abstract}

\section{Keywords : Kependudukan, Desa Lundo, Pemerintahan}

\section{PENDAHULUAN}

Desa adalah kesatuan masyarakat hukum yang mempunyai susunan asli berdasarkan hak asal usul yang bersifat istimewa, memiliki keanekaragaman, partisipasi, otonomi asli, demokratisasi dan pemberdayaan masyarakat (Widjaja, 2003).Potensi desa adalah segenap sumber daya alam dan sumber daya manusia yang dimiliki desa sebagai modal dasar yang perlu dikelola dan dikembangkan bagi kelangsungan dan perkembangan desa.Potensi desa terdiri atas faktor fisik dan non fisik.Potensi fisik-potensi fisik suatu desa meliputi tanah, air, iklim, peternakan dan perikanan, manusia. Sedangkan potensi ialah potensi yang berkaitan erat dengan sumber daya budaya, antara lain : sikap gotong royong dan kreativitas aparatur desa yang mampu mengelola administrasi dan pemerintahan desa secara tertib dan lancer (AM Sari, 2013)

Potensi desa tersebut dimuat pada data administrasi kependudukan desa dan dokumen kependudukan.Administrasi kependudukan adalah rangkaian kegiatan penataan dan penertiban dalam penertiban dokumen dan data kependudukan melalui Pendaftaran Penduduk, Pencatatan Sipil, Pengelolaan Informasi penduduk serta pendayagunaan hasilnya untuk pelayanan publik dan Pembangunan sektor lain. Dokumen kependudukan adalah dokumen resmi yang diterbitkan oleh Instansi Pelaksana yang 
mempunyai kekuatan hukum sebagai alat bukti autentik yang dihasilkan dari pelayanan Pendaftaran Penduduk dan Pencatatan Sipil (Undang-undang Nomor 24 Tahun 2013 Tentang Administrasi Kependudukan).

Desa Lundo merupakan salah satu desa yang terletak di Kecamatan Benjeng Kabupaten Gresik. Desa Lundo terdiri dari 6 dusun yaitu Dusun Lundo, Dusun Ngegot, Dusun Patuk, Dusun Telbek,Dusun Jemek,dan Dusun Gempal.Penduduk Dusun Lundo mayoritas bermatapencarian sebagai petani, karena sebagaian penduduk banyak yang memiliki ladang/kebun yang luasnya berhektarhektar.Karena penduduknya banyak yang memiliki ladang yang luas,desa lundo merupakan desa yang sejuk yang dikelilingi banyak persawahan.Selain berkebun masyarakat desa lundo banyak yang berternak sapi,kamping dan hewan ternak lainnya.

\section{METODE PELAKSANAAN}

Metode yang dilakukan dalam pelaksanaan program pada Divisi Kependudukan adalah dengan melakukan pendekatan dan meminta ijin kepada staff desa terkait dengan tujuan untuk pengambilan data kependudukan Desa Lundo dan survey primer.Data tersebut terdiri dari data primer dan data sekunder.Data primer yaitu terdiri dari hasil wawancara dengan Kepala kasun mengenai batas desa yang kemudian diolah menjadi peta administrasi Desa Lundo serta data kependudukan berupa profil desa yang kemudian data tersebut dianalisis.Selain data primer, data yang dibutuhkan adalah data sekunder yang terdiri dari peta RBI dan data Kecamatan Dalam Angka. Peta RBI atau Peta Rupa Bumi Indonesia adalah peta dasar yang memberikan informasi secara khusus untuk wilayah darat (Nisrina Niwar Hisanah, 2015). Peta RBI biasa disebut juga denga Peta Topografi atau Peta Dasar.Peta dasar adalah peta yang di gunakan sebagai dasar pembuatan peta lainnya. Untuk pembuatan peta tematik, peta dasar adalah peta yang berisi semua data-data tematis yang akan di gambarkan. Peta RBI biasanya di gunakan sebagai dasar pembuatan peta tematik, di perlukan data-data topografi dan dari peta itulah data-data tematis akan di gambarkan (Yusuf, 2012). Data-data tersebut kemudian diolah menjadi peta maupun analisis potensi desa.Secara jelas kerangka metode pelaksanaan dapat dilihat pada gambar 1 .

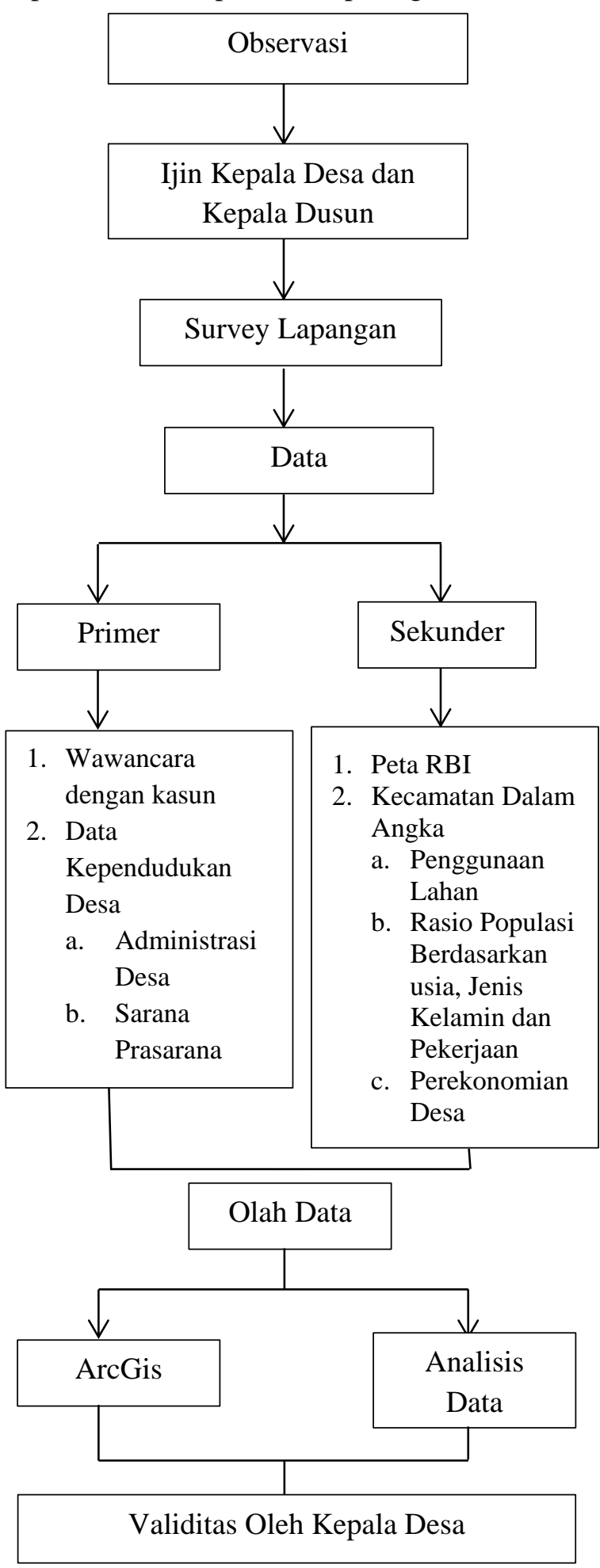

Gambar 1. Kerangka Metode Pelaksanaan 


\section{HASIL DAN PEMBAHASAN}

Berdasarkan data yang telah diperoleh dapat diketahui bahwa Desa Lundo merupakan salah satu desa di Kecamatan Benjeng, Kabupaten Gresik yang terletak di $7^{\circ} 17^{\prime} 36.90^{\prime \prime}$ S $112^{\circ} 28^{\prime} 25.85$ Edan memiliki 6 dusun yaitu : Lundo, Telbek, Jemek, Ngegot, Patuk dan Gempol serta 6 RT dan 10 RW dengan luas wilayah 2,82 $\mathrm{Km} 2$ dan batas administrasi yaitu : Sebelah utara :Desa Sedapur Kelagen Sebelah Selatan :Desa Temuireng

Sebelah Barat :DesaBalungkulon,

Desa Balungmojo dan

DesaBalungtunjung

Sebelah Timur :Desa Banjaragung

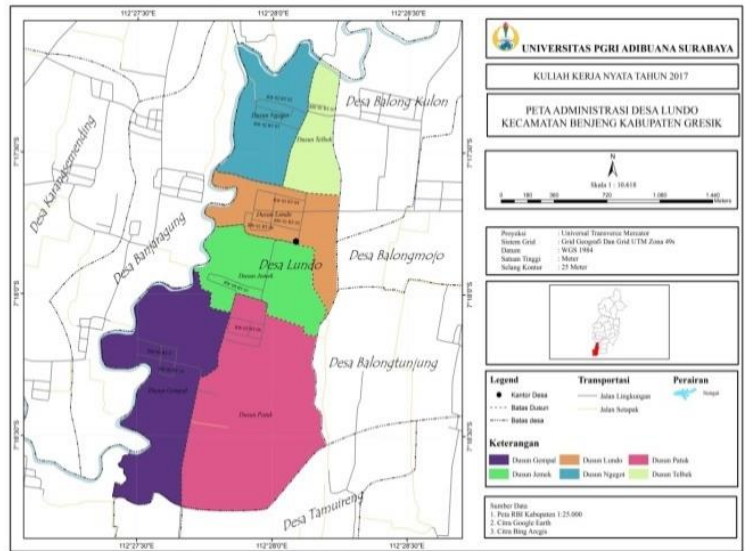

Gambar 2. Peta administrasi Desa Lundo

Desa Lundo berada di ketinggian +4 meter di atas permukaan laut.Penggunaan lahan di Desa Lundo terdiri dari Tanah sawah sebesar $149 \mathrm{Ha}$ , tanah kering sebesar 82,12 $\mathrm{Ha}$, bangunan/perkarangan sebesar $33,00 \mathrm{Ha}$, dan lain-lain sebesar 17,90 Ha.

\section{Penggunaan Lahan}

\author{
- Tanah sawah \\ - tanah kering \\ - bangunan/perkarangan \\ a lain-lain
}
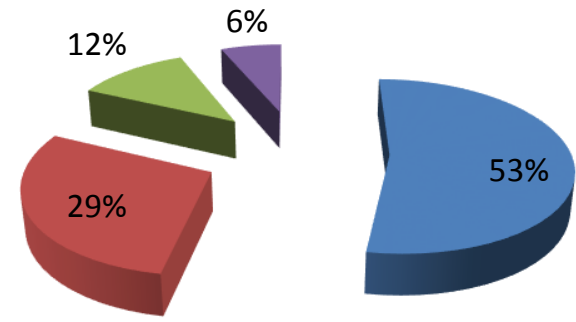

Gambar 3. Penggunaan Lahan Desa Lundo

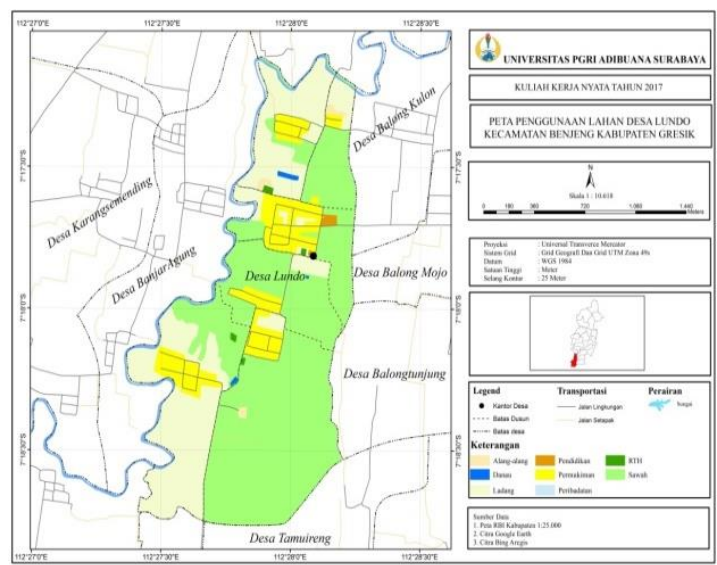

Gambar 4. Peta Penggunaan Lahan Desa

Lundo

Jumlah penduduk di Desa Lundo pada tahun 2015 adalah sebesar 2670 Jiwa yang terbagi menjadi jumlah penduduk laki-laki sebesar 1100 jiwa dan jumlah penduduk perempuan sebesar 2079. Kepadatan penduduk di Desa Lundo adalah sebesar $943 \mathrm{Jiwa} / \mathrm{Km}^{2}$.Jumlah penduduk Desa Lundo secara jelas dapat dilihat pada tabel 1. 
Tabel 1. Jumlah penduduk Desa Lundo Tahun 2013-2015

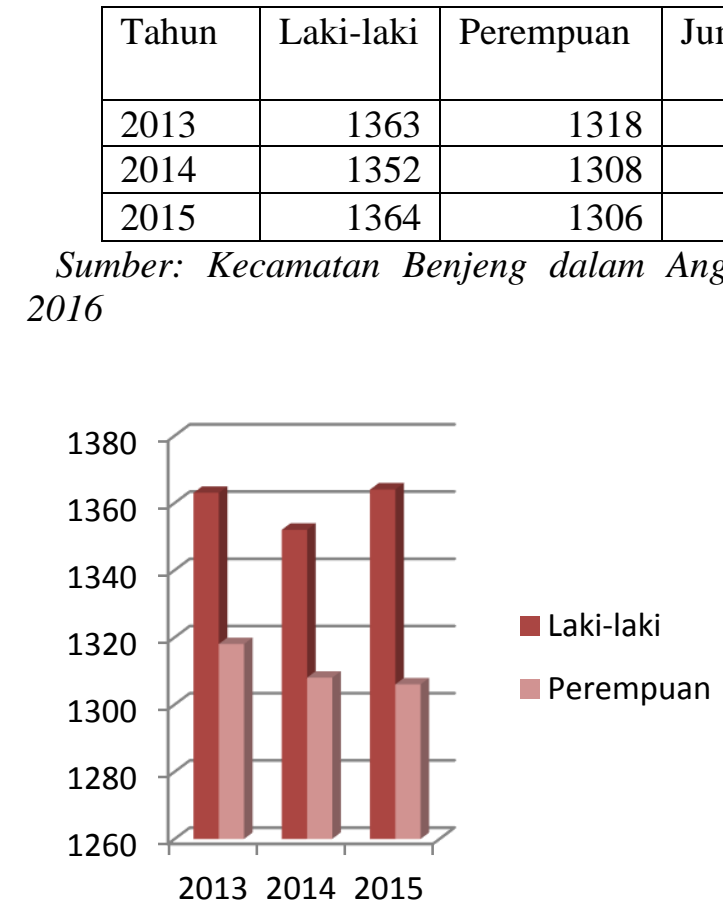

Gambar 5. Jumlah Penduduk Desa Lundo Tahun 2013-2015

Perubahan jumlah penduduk di Desa Lundo dari tahun 2013-2015 disebabkan oleh adanya jumlah penduduk meninggal, jumlah penduduk lahir, jumlah penduduk datang dan jumlah penduduk pindah.Jumlah penduduk meninggal pada tahun 2015 di Desa Lundo adalah sebesar 8 Jiwa.Sedangkan jumlah penduduk lahir adalah sebesar 16 Jiwa.Jumlah penduduk datang pada tahun 2015 adalah sebesar 13 Jiwa serta penduduk yang pindah sebesar 25 Jiwa. Sedangkan jumlah penduduk Desa Lundo berdasarkan usia paling besar adalah berada pada usia 26-40 tahun dan jumlah penduduk terendah berada pada usia 17, secara detail jumlah penduduk berdasarkan usia dapat dilihat pada tabel 2.
Tabel 2. Jumlah Penduduk Desa Lundo Tahun 2015 Berdasarkan usia

\begin{tabular}{|l|l|r|}
\hline No & \multicolumn{1}{|c|}{ Usia } & \multicolumn{1}{c|}{ Jumlah } \\
\hline 1 & $0-5$ & 217 \\
\hline 2 & $6-9$ & 166 \\
\hline 3 & $10-16$ & 277 \\
\hline 4 & 17 & 77 \\
\hline 5 & $18-25$ & 283 \\
\hline 6 & $26-40$ & 670 \\
\hline 7 & $41-59$ & 700 \\
\hline 8 & $>60$ & 280 \\
\hline \multicolumn{2}{|c|}{ Jumlah } \\
\hline
\end{tabular}

\section{Jumlah Penduduk berdasarkan usia}

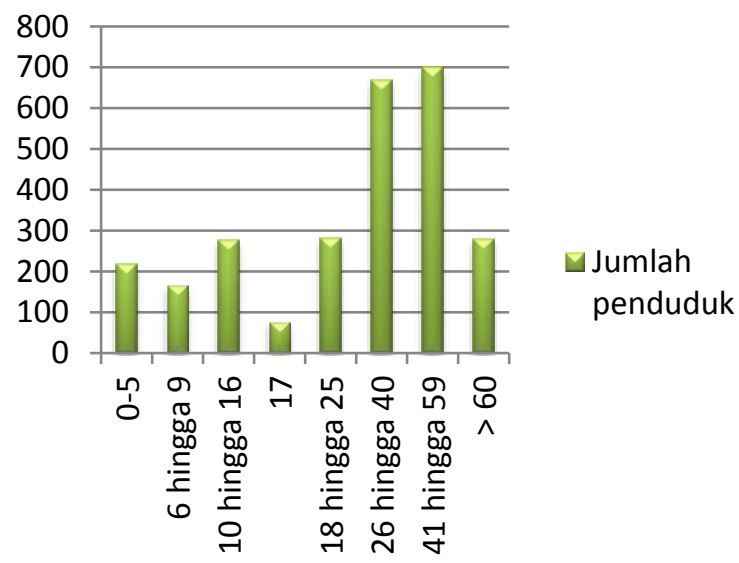

Gambar 6. Jumlah Penduduk Desa Lundo Berdasarkan usia Tahun 2015

Penduduk Desa Lundo berdasarkan mata pencaharian antara lainbekerja dibidang pertanian, industri, konstruksi, perdagangan, angkutan dan lainnya yang dapat dilihat secara detail pada tabel 3 .

Tabel 3. Jumlah Penduduk Berdasarkan Bidang Mata Pencaharian

\begin{tabular}{|l|l|r|}
\hline No & \multicolumn{1}{|c|}{ Usia } & \multicolumn{1}{c|}{ Jumlah } \\
\hline 1 & Pertanian & 1015 \\
\hline 2 & Industri & 185 \\
\hline 3 & Konstruksi & 30 \\
\hline
\end{tabular}




\begin{tabular}{|l|l|r|}
\hline No & \multicolumn{1}{|c|}{ Usia } & \multicolumn{1}{c|}{ Jumlah } \\
\hline 4 & Perdagangan & 305 \\
\hline 5 & Angkutan & 25 \\
\hline 6 & Jasa & 180 \\
\hline 7 & Lainnya & 215 \\
\hline
\end{tabular}

Sumber : Kecamatan Benjeng dalam Angka 2016

\section{Jumlah penduduk Berdasarkan Mata Pencaharian}

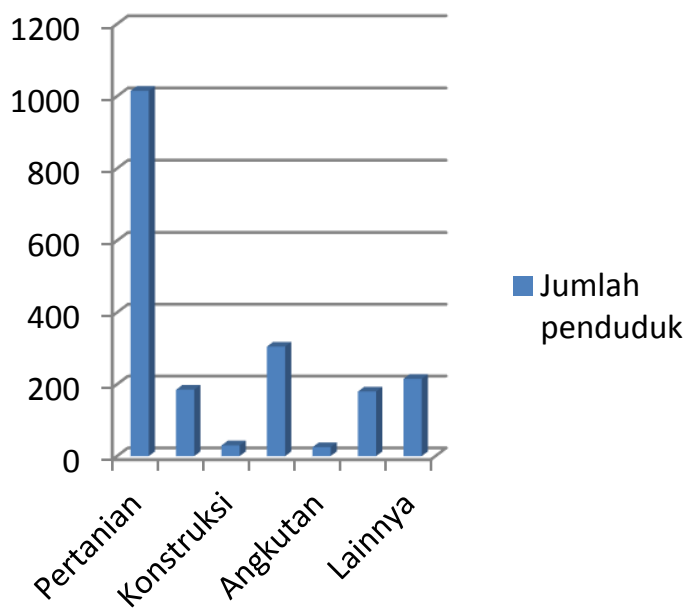

Gambar 7. Jumlah Penduduk Desa Lundo Berdasarkan Mata Pencaharian Tahun 2015

Ketersediaan sarana di Desa Lundo juga dapat menentukan potensi desa yang dapat dilihat dari sarana pendidikan, peribadatan dan kesehatan.Ketersediaan sarana di Desa Lundobaik pendidikan maupun kesehatan dapat dikatakan masih belum memenuhi baik dilihat dari segi kualitas dan kuantitasnya. Berdasarkan SNI 03-1733-2004Tata cara perencanaan lingkungan perumahan Standar sarana dalam sebuah wilayah antara lain :

a. TK dengan penduduk pendukung 1.250 jiwa luas kapling antara $216-500 \mathrm{~m} 2$ b. SD dengan penduduk pendukung 1.600 jiwa luas kapling antara $633-2000$ $\mathrm{m} 2$

c. SMP dengan penduduk pendukung 4.800 jiwa luas kapling antara 2.282 - 9000 $\mathrm{m} 2$ d. SMA dengan penduduk pendukung 4.800 jiwa luas kapling antara $3.835-$ $12.500 \mathrm{~m} 2$

e. Posyandu penduduk pendukung 1.250 jiwa

f. Balai pengobatan warga penduduk pendukung 2.500 jiwa

g. BKIA/ Klinik Bersalin penduduk pendukung 30.000 jiwa

h. Tempat praktek dokter penduduk pendukung 5.000 jiwa

i. Mushola/ langgar penduduk pendukung 250 jiwa

j. Masjid warga penduduk pendukung 2.500 jiwa

k. Masjid lingkungan (kelurahan) penduduk pendukung 30.000 jiwa

Sarana pendidikan dapat dilihat secara detail pada tabel 4.

Tabel 4. Jumlah Sarana Pendidikan Desa Lundo

\begin{tabular}{|c|c|c|}
\hline No & Jenjang & Jumlah \\
\hline 1 & \multicolumn{2}{|l|}{ Negeri } \\
\hline & TK & - \\
\hline & SD & 1 \\
\hline & SMP & - \\
\hline & SMA & - \\
\hline 2 & \multicolumn{2}{|l|}{ Swasta } \\
\hline & TK & 1 \\
\hline & SD & - \\
\hline & SMP & - \\
\hline & SMA & - \\
\hline
\end{tabular}

Sumber : Kecamatan Benjeng dalam Angka 2016

Sedangkan sarana kesehatan di Desa Lundo baik rumah sakit, puskesmas, maupun praktik dokter belum tersedia.Sarana kesehatan di Desa Lundo didominasi oleh posyandu dengan kualitas belum memenuhi.

Tabel 5. Sarana Kesehatan Desa Lundo

\begin{tabular}{|l|l|r|}
\hline No & Jenis & Jumlah \\
\hline 1 & Rumah Sakit Umum & 0 \\
\hline 2 & Rumah Sakit Bersalin & 0 \\
\hline
\end{tabular}




\begin{tabular}{|l|l|r|}
\hline No & Jenis & Jumlah \\
\hline 3 & Poli Klinik & 0 \\
\hline 4 & Puskesmas & 0 \\
\hline 5 & Pustu & 0 \\
\hline 6 & Praktek Dokter & 0 \\
\hline 7 & Rumah Bersalin & 0 \\
\hline 8 & Prakek Bidan & 1 \\
\hline 9 & Poskesdes & 1 \\
\hline 10 & Polindes & 0 \\
\hline 11 & Posyandu & 6 \\
\hline 12 & Apotek & 0 \\
\hline
\end{tabular}

Sumber : Kecamatan Benjeng dalam Angka 2016

Untuk sarana peribadatan di Desa Lundo berupa masjid dan mushola cukup memenuhi dari segi kuantitasnya. Hal tersebut dikarenakan kebanyakan masyarakat Desa Lundo beragama islam yaitu sebesar 2.650 jiwa. Jumlah sarana peribadatan secara detail dapat dilihat pada tabel 6.

Tabel 6. Jumlah Sarana Peribadatan

\begin{tabular}{|l|l|l|}
\hline No & Jenis Peribadatan & Jumlah \\
\hline 1 & Masjid & 4 \\
\hline 2 & Langgar & 7 \\
\hline 3 & Gereja & - \\
\hline 4 & Pura & - \\
\hline 5 & Vihara & - \\
\hline
\end{tabular}

Sumber : Kecamatan Benjeng dalam Angka 2016

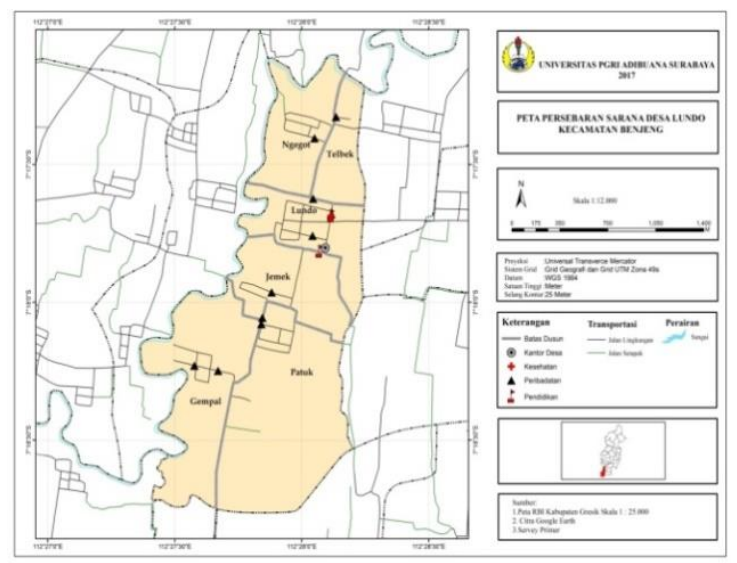

Gambar 8. Peta Persebaran Sarana Desa Lundo

Selain dari ketersediaan sarana potensi desa dapat dilihat juga dari kondisi prasarana yang meliputi jaringan jalan, listrik, jaringan drainase, air bersih dan persampahan. Jaringan jalan di Desa Lundo terdiri dari jalan lokal dan jalan lingkungan dengan permukaan jalan aspal sebesar $0 \%$, paving $40 \%$, jalan diperkeras $60 \%$ serta jalan tanah 0\%. Kualitas jalan di Desa Lundo masih buruk hal tersebut di buktikan dengan banyaknya jalan berlubang dan rusak yang menyebabkan genangan saat musim penghujan.Selain itu, tidak tersedianya jaringan drainase baik primer, sekunder, maupun primer di sepanjang jalan di Desa Lundo yang juga menyebabkan terjadinya banjir di Desa Lundo.

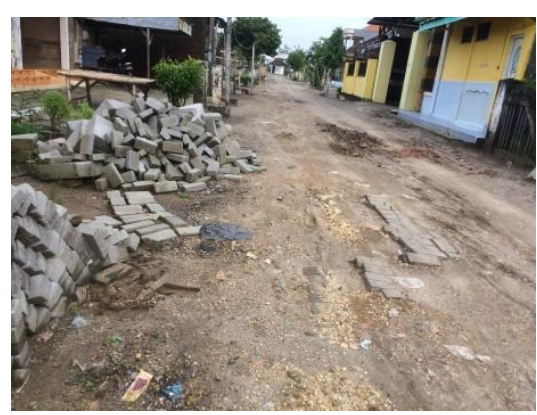

Gambar 9.Kualitas Jalan Desa Lundo

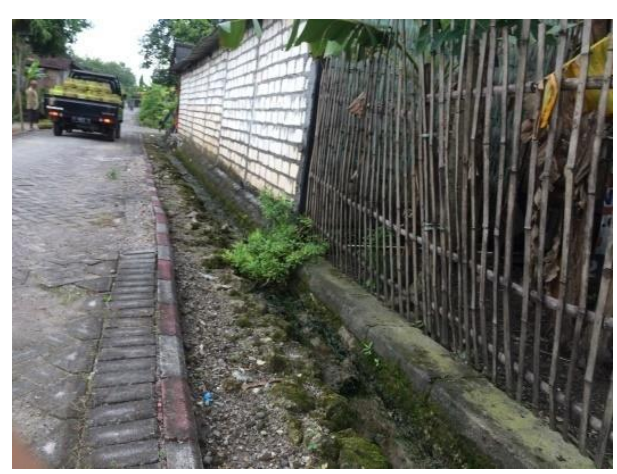

Gambar 10. Kondisi Drainase di Jalan Lingkungan

Jaringan listrik di Desa Lundo sudah hampir terpenuhi di seluruh dusun.Akan tetapi, kualitas jaringan listrik belum maksimal.Warga harus bergantian menggunakan listrik dikarenakan daya listrik yang kecil.Sedangkan,jaringan air bersih di Desa Lundo belum maksimal, masyarakat mendapatkan air bersih dari air tandon atau mata air.Serta jaringan persampahan di Desa Lundo belum dikelola dengan baik.Hal tersebut dikarenakan belum tersedianya TPS di Desa Lundo, masyarakat masih membuang 
sampah di sungai, selokan, tanah kosong maupun dibakar.

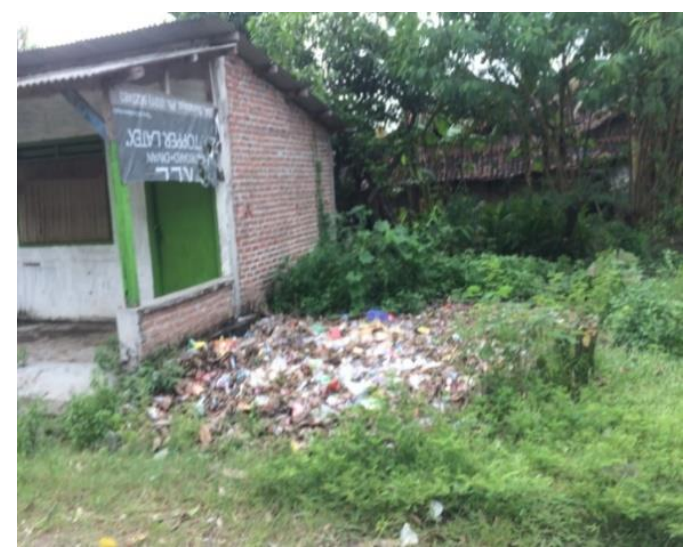

Gambar 11. Sampah di Tanah Kosong

Potensi Desa Lundo juga dapat dilihat dari segi ekonomi yaitu tingkat produktivitas pertanian dan peternakan Desa Lundo.Pertanian di Desa Lundo merupakan potensi unggulan karena luas lahan di Desa Lundo masih didominasi oleh persawahan.Produktivitas pertanian Desa Lundo dapat dilihat pada tabel 6 .

Tabel 6. Produktivitas Pertanian Desa Lundo Tahun 2016

\begin{tabular}{|l|l|r|}
\hline No & \multicolumn{1}{|c|}{ Jenis } & Jumlah (Ton) \\
\hline 1 & Padi & 2455 \\
\hline 2 & Jagung & 589 \\
\hline 3 & Kedelai & - \\
\hline 4 & Kacang tanah & - \\
\hline 5 & Kacang Hijau & 110.6 \\
\hline
\end{tabular}

Sumber : Kecamatan Benjeng dalam Angka 2016

\section{Produktivitas \\ Pertanian}

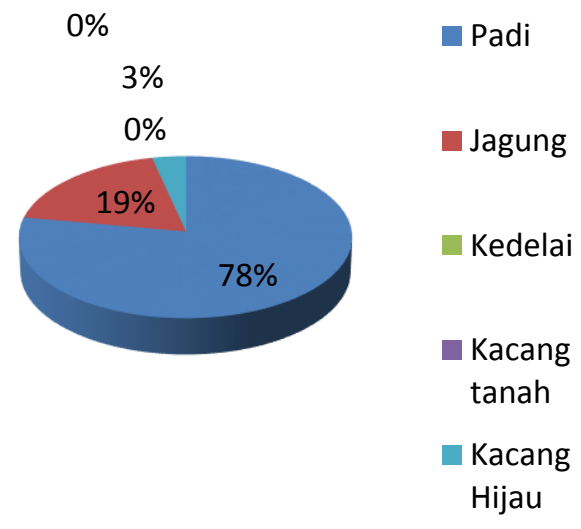

Gambar 12. Produktivitas Pertanian Desa Lundo Tahun 2016

Sedangkan peternakan di Desa Lundo juga berkembang dengan baik.Peternakan di Desa Lundo terdiri dari sapi, kambing, ayam dan itik. Jumlah populasi peternakan di Desa Lundo secara detail dapat dilihat pada tabel 7 .

Tabel 7. Produktivitas Peternakan Desa Lundo Tahun 2016

\begin{tabular}{|l|l|r|}
\hline No & \multicolumn{1}{|c|}{ Jenis } & \multicolumn{1}{c|}{ Jumlah } \\
\hline 1 & Sapi & 160 \\
\hline 2 & Kambing & 126 \\
\hline 3 & Ayam Kampung & 1500 \\
\hline 4 & Itik & 200 \\
\hline
\end{tabular}

Sumber : Kecamatan Benjeng dalam Angka 2016

Selain, pertanian dan peternakan potensi Desa Lundo dapat dilihat berdasarkan industry kecil serta kerajinan yang dimiliki oleh masyarakat sekitar Desa Lundo.Industri kecil dan kerajinan di Desa Lundo cukup banyak dan bervariasi yang tersebar merata di 6 dusun di Desa Lundo. Industri kecil dan kerajinan tersebut diantaranya adalah

1. Industri Kecil Sablon

2. Industri Kecil Jamu 
3. Kerajinan Kerai bambu

4. Kerajinan kurungan ayam

5. Industri Kecil keset, dll

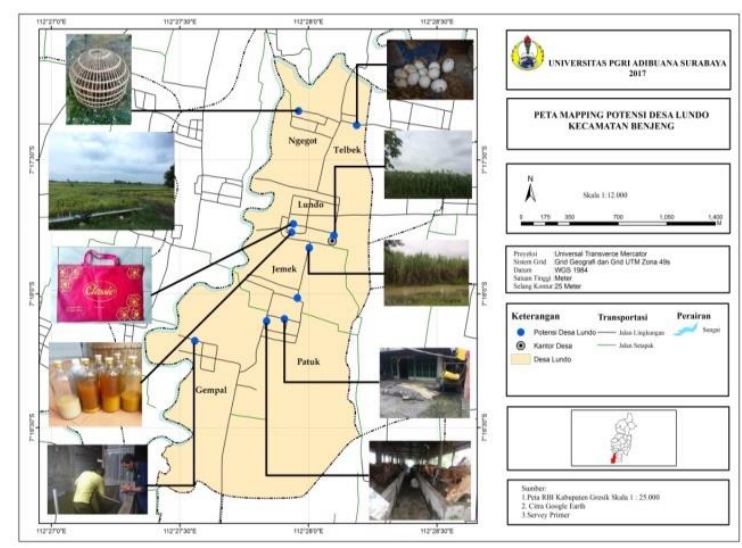

Gambar 13. Peta Mapping Potensi Desa Lundo

Dalampeningkatan pengembangan potensi di Desa Lundo perlu adanya pertisipasi aparat pemerintahan, yaitu salah satunya melalui penyusunan data yang dimaksudkan untuk mendokumentasikan potensi desa yang terdiri dari sarana, prasarana, kependudukan dan ekonomi.Berdasarkan hal tersebut devisi kependudukan memiliki program dalam peningkatan pendataan melalui sosialisasi aplikasi "Population" untuk memperkenalkan aplikasi offline yang dapat mempermudah staf desa terkait untuk melakukan pendataan dari segi kependudukan.Sedangkan, untuk pengolahan data desa devisi kependudukan melakukan pemetaan yang bertujuan untuk menvisualisasikan data tersebut menjadi lebih menarik.Pemetaan tersebut terdiri dari peta administrasi, peta penggunaan lahan, peta persebaran sarana dan peta potensi desa.

\section{SIMPULAN DAN SARAN}

Berdasarkan data Kecamatan Dalam Angka 2016 maupun profil Desa yang didapat, Desa Lundo merupakan desa yang berpotensi untuk berkembang dengan baik. Hal tersebut dibuktikan dengan tingginya potensi utamanya di Sumber Daya Alam berupa hasil pertanian yang produktivitasnya tinggi.akan tetapi, potensi Sumber Daya Alam yang tinggi tersebut tinggi diimbangi dengan sarana prasarana yang mendukung. Sarana di Desa Lundo baik kualitas maupun kuantitasnya masih belum maksimal.Sedangkan prasarananya juga masih belum baik.Disamping hal tersebut, data administrasi Kependudukan di Desa Lundo sudah terdokumentasi dengan cukup baik.

Saran yang dapat diberikan devisi kependudukan dalam hal kependudukan dan pendataan, yaitu :

1. Meningkatkan kualitas staff pemerintahan terkait dengan memberikan penyuluhan lebih mendalam mengenai penginputan data kependudukan.

2. Meningkatkan jumlah staff pemerintahan di bidang pendataan kependudukan.

\section{DAFTAR PUSTAKA}

Yakin, Ainul. 2016. Data Profil Desa Dan Kelurahan Desa Lundo, 1. Data Potensi Desa, 2. Data Perkembangan. Gresik.

Anonim. Kecamatan Benjeng Dalam Angka. 2016. www.bps.go.id.

Hisanah, Nisrina. 2015. Kajian Teknis Penerapan Generalisasi Peta Bumi Indonesia dari Skala 1:50.000 menjadi skala 1:250.000. Jurnal Geodesi Undip.

Undang-Undang Republik Indonesia Nomor 24 Tahun 2013 Tentang Administrasi Kependudukan. 2013. Jakarta

SNI 03-1733-2004 Tentang Tata cara perencanaan lingkungan perumahan di perkotaan .BSN.

Mekar, Asih. 2013. Pemberdayaan Sistem Pemerintah dan Potensi Desa Pada Kabupaten Pringsewu Berbasis Web.

Sune, Nawir. 2011. Modul Praktikum Kartografi. Gorontalo.UNG.

Widjaja. 2003. Otonomi Desa. Rajawali Pers: Depok.

http://obstetriginekologi.com/artikel/pengertian +peta+tematik.html

http://id.wikipedia.org/wiki/Peta_tematik 